\title{
Situational Depression of Patients with Dyscirculatory Encephalopathy
}

\author{
Inna Chemeresiuk* and Heorhy Hontaruk \\ Odessa National Medical University, Ukraine \\ *Corresponding author: G Chemeresyuk, Department of Neurology and Neurosurgery, Odessa National Medical \\ University, Ukraine
}

\begin{tabular}{|c|c|}
\hline ARTICLE INFO & ABSTRACT \\
\hline Received: 㓞August 10, 2019 & Citation: Inna Chemeresiuk Heorhy Hontaruk. Situational Depression of Patients \\
\hline Published: & $\begin{array}{l}\text { with Dyscirculatory Encephalopathy. Biomed J Sci \& Tech Res 20(5)-2019. BJSTR. } \\
\text { MS.ID.003510. }\end{array}$ \\
\hline
\end{tabular}

\section{Opinion}

Very often, doctors of various specialties must deal with situational depression of elderly patients. In this regard, many questions arise about the plan of examination and treatment of such patients. As an example, I would like to describe a typical case with patient's 67 years old. Complaints: general weakness, fatigue, decreased mood background, tearfulness, insomnia, anxiety, headaches, dizziness, increased blood pressure, decreased memory, decreased appetite. Anamnesis of the disease: the patient suffers from high blood pressure for several years. The above complaints appeared after the death of her husband; hypertensive crises joined. It was treated on an outpatient basis. Neurological status: cranial nerves without pathology. Tendon and periosteal reflexes are alive, without a distinct side difference. There are no pathological reflexes, meningeal signs. Sensitivity is saved. In the Romberg position was observing uniform staggering, tremors of the eyelids and fingers of outstretched arms. Coordination tests were satisfactory. Severe autonomic stigma exists vasomotor reaction on the face, Trousseau spots. Hyperhidrosis. Psyche: comprehensively oriented, contact, fixed on its painful manifestations, prone to tearfulness. Criticism is maintained.

\section{Psychological Status}

During testing on the New acting scale of depression DUODECIM, the patient scored a total of 25 points, which indicates the presence of depression. The patient was evaluated for suicide using the Columbia University Scale to assess the severity of suicidal manifestations (C-SSRS). According to this scale, there is currently no suicidal tendency. The patient passed the PASAT audio test and SDMT test. According to the survey and tests, the decrease in vital activity is manifested for the patient in both mental and physical functions. Her thinking is difficult, associations are avaricious, thoughts revolve around one topic: the hopelessness of one's own life in the light of her husband's death, her own guilt and helplessness. Noteworthy is the deterioration of memory, mainly short-term, on current events, a marked decrease in concentration. The world around her does not attract her; everything seems unpleasant and painful; only memories of unpleasant events emerge from the past. The patient notes helplessness in front of the reality surrounding her. Due to the decline in vital activity, the pace of mental processes is slowed down, the patient is inert, but easily excitable. She does not want anything; she is seized by apathy. Thoughts revolve around the same topics, mainly around the death of her husband, loneliness and illness. The same severity manifests itself in physical functions. This can be seen already in the pose and walk-the patient is hunched over, inactive, the mask of suffering on the face, the patient often begins to cry during a conversation. A decrease in vital activity is reflected in autonomic functions: this is a decrease in appetite, and frequent hypertensive crises with elements of diencephalic crisis states; the patient notes a decrease in salivation (the usual dry mouth in her recently), notes a decrease in peristalsis, a complete lack of sexual desire. The skin is flabby and dry.

The patient notes a sleep disturbance: she wakes up very early, in the first or second hour of the night, and the rest spends without sleeping. Patient's symptoms of depression are combined with signs of anxiety. The anxiety-depressive syndrome includes 
sensitivity to danger, predicting failure, a negative image of the past, and a negative image of the future, impaired planning, loss of life prospects, experience of the meaninglessness of the present. The psychological phenomenology of the anxiety-depressive state of the patient is associated with the formation of a consistent negative image of the past, future and present. The predominance of a negative image of the future in the structure of this state determines the dominance of anxiety, the predominance of a negative image of the past and present - depression.

The patient revealed the predominance of a passive personality position, avoiding failure is the leading motivational orientation, a high level of awareness of existing problems through the prism of dissatisfaction and pessimistic assessment of their prospects; a tendency to think, inertness in decision making, a pronounced depth of experience, skepticism, self-criticism, a pronounced selfdoubt, in their capabilities. The style of interpersonal behavior is manifested by traits of dependence. The patient's afflicted need is aggravated, such as the need for understanding, love, a friendly attitude toward her - she is one of the leading ones, never fully saturated and at the same time primarily frustrated need, which largely determines the area of traumatic effects. The patient's thinking style is predominantly verbal: the perception, processing and reproduction of information is based on the word, semantic basis, and meaningful analysis. In stress, she showed a tendency to stop reactions (blocking activity).

Given the data of psychological, mental and neurological status, we can make the following conclusion:

a) Situational depression with the background of mixed origin dis circulatory encephalopathy.

b) Recommendation: observation by a therapist, neurologist, psychologist / psychotherapist. Outpatient, inpatient and spa treatment are indicated.

c) I emphasize that the treatment of such patients is carried out by doctors of various specialties. Therefore, she was recommended the supervision of a therapist, neurologist, psychologist/ psychotherapist; outpatient, inpatient and spa treatment were indicated.

\section{Acknowledgement}

None.

\section{Conflict of Interest}

No conflict of interest.
ISSN: 2574-1241

DOI: 10.26717/BJSTR.2019.20.003510

Inna Chemeresiuk. Biomed J Sci \& Tech Res

(C) This work is licensed under Creative

Submission Link: https://biomedres.us/submit-manuscript.php

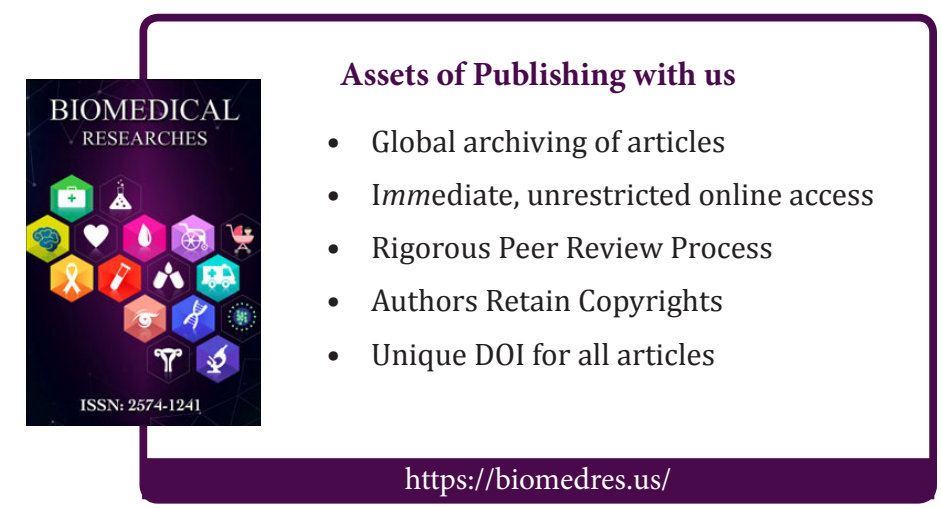

